\title{
Педіатрія
}

УДК 616.12-008.331.1-053.2-003.96-085

®Т. В. Гищак

Національний медичний університет імені О. О. Богомольия, Київ

\section{СТАН ТОЛЕРАНТНОСТІ СЕРЦЕВО-СУДИННОЇ СИСТЕМИ ДО ФІЗИЧНОГО НАВАНТАЖЕННЯ ТА ХАРАКТЕРИСТИКА МІОКАРДІАЛЬНИХ РЕЗЕРВІВ ЗА РЕЗУЛЬТАТАМИ ВЕЛОЕРГОМЕТРИЧНОЇ ПРОБИ В ДІТЕЙ 3 ПЕРВИННОЮ АРТЕРІАЛЬНОЮ ГІПЕРТЕНЗІЄЮ}

СТАН ТОЛЕРАНТНОСТІ СЕРЦЕВО-СУДИННОЇ СИСТЕМИ ДО ФІЗИЧНОГО НАВАНТАЖЕННЯ ТА ХАРАКТЕРИСТИКА

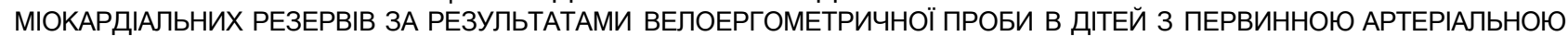
ГІПЕРТЕНЗІЕЮ. У статті наведено результати велоергометричної проби в 90 дітей віком 11-17 років з нормальним і підвищеним артеріальним тиском та їх порівняльну характеристику залежно від форми первинної артеріальної гіпертензії (ПАГ). Результати дослідження свідчать про те, що гіпертензивна реакція ЧСС, САТ і ДАТ полягає не тільки у більш високих іХ значеннях на висоті фізичного навантаження, але і в коливаннях вище та нижче початкових значень, діапазон і час виникнення яких у фазу відпочинку після проби різняться у хлопчиків та дівчаток і залежать від форми ПАГ (лабільна, стабільна I ст. або стабільна II ст.). Визначено, що лабільна гіпертензія формується за недостатніх функціональних резервів міокарда та супроводжується підвищеним і неекономним їх витрачанням. Стабілізація гіпертензії' супроводжується компенсаторними змінами, що проявляються перерозподілом судинного і серцевого функціональних резервів таким чином, що покращується ефективність роботи серця. Виявлені особливості адаптації' до фізичного навантаження в дітей з різними формами ПАГ розкривають патогенетичні особливості процесів стабілізації' гіпертензії' та є перспективними щодо прогнозування стабільного і лабільного перебігу ПАГ та розробки відповідних лікувальних і профілактичних заходів.

СОСТОЯНИЕ ТОЛЕРАНТНОСТИ СЕРДЕЧНО-СОСУДИСТОЙ СИСТЕМЫ К ФИЗИЧЕСКОЙ НАГРУЗКЕ И ХАРАКТЕРИСТИКА МИОКАРДИАЛЬНЫХ РЕЗЕРВОВ ПО РЕЗУЛЬТАТАМ ВЕЛОЭРГОМЕТРИЧЕСКОЙ ПРОБЫ У ДЕТЕЙ С ПЕРВИЧНОЙ АРТЕРИАЛЬНОЙ ГИПЕРТЕНЗИЕЙ. В статье представлены результаты велоэргометрической пробы у 90 детей в возрасте 11-17 лет с нормальным и повышенным артериальным давлением и их сравнительная характеристика в зависимости от формы первичной артериальной гипертензии (ПАГ). Результаты исследования свидетельствуют о том, что гипертензивная' реакция' ЧСС,' САД' и' ДАД' заключается' не' только' в' их' более' высоких' значениях' на' высоте' физической нагрузки, но и в колебаниях выше и ниже первоначальных значений, диапазон и время возникновения которых в фазе отдыха после пробы отличаются у мальчиков и девочек и зависят от формы ПАГ (лабильная, стабильная I ст. или стабильная II ст.). Определено, что лабильная гипертензия формируется при недостаточных функциональных резервах миокарда и сопровождается повышенным и неэкономным их расходованием. Стабилизация гипертензии сопровождается компенсаторными изменениями, которые проявляются перераспределением сосудистого и сердечного функциональных резервов таким образом, что улучшается эффективность работы сердца. Выявленные особенности адаптации к физической нагрузке у детей с разными формами ПАГ раскрывают патогенетические особенности процессов стабилизации гипертензии и являются перспективными относительно прогнозирования стабильного и лабильного течения ПАГ и разработки соответствующих лечебных и профилактических мероприятий.

STATE OF THE CARDIOVASCULAR SYSTEM'S TOLERANCE TO PHYSICAL ACTIVITY AND CHARACTERIZATION OF MYOCARDIAL RESERVE AS A RESULT OF BICYCLE STRESS TEST IN CHILDREN WITH PRIMARY HYPERTENSION. The results of bicycle stress test in 90 children 11-17 years with normal and high blood pressure and their comparative characteristics depending on the shape of the primary arterial hypertension (PAH) was presented. These results suggest, that the hypertensive reaction in heart rate, systolic and diastolic blood pressure is not only in their higher values at the height of physical activity, but also in the fluctuations above and below the initial value, range and time of which are in a phase of rest after the test depends on the form of pah (labile, stable stage $\mathrm{i}$ or stable stage ii.). The labile hypertension formed with insufficient functional reserves infarction and accompanied by increased and wasteful spending of these reserves. Stabilization of hypertension is accompanied by compensatory changes that occur redistribution of cardiac and vascular function reserves a way that improves the efficiency of the heart's work. Revealed features of adaptation to physical activity in children with different forms of PAH reveal pathogenetic features of hypertension and stabilization processes are promising with respect to the prediction of stable and labile flow pah and the development of appropriate therapeutic and preventive measures.

Ключові слова: артеріальна гіпертензія, діти, велоергометрія.

Ключевые слова: артериальная гипертензия, дети, велоэргометрия.

Key words: arterial hypertension, children, bicycle stress test.

ВСТУП. Останнім часом проблеми, що пов'язані з реакцією дітей шкільного віку на фізичне навантаження, все частіше привертають увагу педіатрів і науковців. Доведено, що як гіподинамія, так і неконтрольовані заняття спортом є важливими факторами ризику розвитку первинної артеріальної гіпертензії (ПАГ) у дітей $[1,2] .3$ іншого боку, відомо, що правильно підібрані режими тренувань мають лікувально-профілактичний 
ефект щодо нормалізації артеріального тиску (АТ) у дітей і осіб молодого віку $[3,4]$. Проте механізми, що лежать в основі впливу фізичного навантаження на артеріальний тиск, ще остаточно не з'ясовані.

Одним із найбільш точних методів, що дозволяють вивчати реакцію організму на фізичне навантаження, $€$ функціональні проби із застосуванням велоергометра. Велоергометричне дослідження дає можливість надати характеристику толерантності до фізичного навантаження, процесів споживання кисню міокардом і міокардіальних резервів, що мають значення в загальній адаптації організму [5].

Мета дослідження - з'ясувати особливості толерантності серцево-судинної системи до фізичного навантаження і резервні можливості міокарда в дітей з різними формами ПАГ.

МАТЕРІАЛИ ТА МЕТОДИ. В дослідження було включено 90 дітей (51 хлопчика і 39 дівчаток) віком 11-17 років, які проходили обстеження і лікування на базі дитячої клінічної лікарні № 3 м. Києва. Серед них 12 дітей мали нормальний АТ і склали контрольну групу, інші ввійшли до трьох основних груп: перша група - діти із стабільною ПАГ ІІ ст., друга - діти із стабільною ПАГ І ст., третя - діти з лабільною ПАГ.

У дослідження не було включено дітей з ознаками гострої респіраторної інфекції, хронічними захво- рюваннями в стадії загострення, кардитами, захворюваннями щитоподібної, підшлункової, надниркових залоз, інфекцією сечовивідних шляхів.

Усім дітям проведено загальноклінічне обстеження, добовий моніторинг артеріального тиску (ДМАТ) і пробу за методикою PWC $_{170}$ на велоергометричному комплексі «Кардіолаб+вело» із застосуванням велоергометра «Kettel».

Серед показників велоергометри обчислювалися такі: $\mathrm{PWC}_{170}$ - фізична працездатність; максимальне споживання кисню (МСK) і відносне максимальне споживання кисню (BMCK); хронотропний резерв $(\mathrm{XP})$; індекс хронотропного резерву (XP) інотропний резерв (IP); індекс інотропного резерву (IP); серцевий навантажувальний індекс (CHI); коефіцієнт витрачання резервів міокарда (КВРМ); індекс ефективності роботи серця (IEPC).

Для оцінювання результатів застосовувались загальноприйняті методи математичної статистики 3 обчисленням достовірної різниці величин за коефіцієнтом Стьюдента.

РЕЗУЛЬТАТИ ДОСЛІДЖЕННЯ ТАЇХ ОБГОВОРЕН-

НЯ. Результати велоергометричної проби наведено в таблицях 1 і 2.

Як видно з даних таблиці 1, у хлопчиків контрольної групи на 5-й хв фази спокою після прове-

Таблиця 1. Результати велоергометричної проби в дітей з артеріальною гіпертензією порівняно 3 контрольною групою

\begin{tabular}{|c|c|c|c|c|c|c|c|c|}
\hline \multirow[b]{2}{*}{ Показник } & \multicolumn{2}{|c|}{ 1. Стабільна ПАГ ॥ Ст. } & \multicolumn{2}{|c|}{ 2. Стабільна ПАГ І ст. } & \multicolumn{2}{|c|}{ 3. Лабільна ПАГ } & \multicolumn{2}{|c|}{ 4. Контрольна група } \\
\hline & $\begin{array}{c}\text { хлопчики, } \\
\text { п }=14\end{array}$ & $\begin{array}{c}\text { Аівчатка, } \\
\quad \pi=6\end{array}$ & $\begin{array}{c}\text { хлопчики, } \\
\text { п }=15\end{array}$ & $\begin{array}{c}\text { Аівчатка, } \\
\quad \text { п }=11\end{array}$ & $\begin{array}{c}\text { хлопчики, } \\
\text { п }=15\end{array}$ & $\begin{array}{c}\text { Аівчатка, } \\
\quad \pi=17\end{array}$ & $\begin{array}{c}\text { хлопчики, } \\
\text { п }=7\end{array}$ & 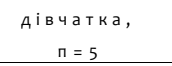 \\
\hline $4 \mathrm{CC}$ 。 & $89,75 \pm 2,59$ & $99,0 \pm 5,03$ & $91,67 \pm 2,41$ & $90,73 \pm 2,61$ & $84,86 \pm 2,03$ & $\begin{array}{r}87,94 \pm \\
2,08 * 1-3 \\
\end{array}$ & $89,29 \pm 3,08$ & $92,0 \pm 1,08$ \\
\hline CAT。 & $\begin{array}{c}130,69 \pm \\
2,20^{11}-4, \quad 1-3 \\
\end{array}$ & $\begin{array}{l}120,80 \pm \\
2 \stackrel{g y * 1-4 ; D}{ }\end{array}$ & $\begin{array}{r}126,90 \pm \\
+\quad 54 * 2-4,2-3 \\
\end{array}$ & $\begin{array}{l}116,20 \pm \\
195 * 2-4 ; \pi\end{array}$ & $\begin{array}{l}119,29 \pm \\
182 * 3-4\end{array}$ & $106,0 \pm 1,78^{\circ}$ & $101,86+1,56$ & $102,20 \pm 2,06$ \\
\hline А АТ० & $\begin{array}{l}76,31 \pm \\
1,04 * 1 \cdot 4 \\
\end{array}$ & $\begin{array}{r}76,33 \pm \\
243 * 1-4 \\
\end{array}$ & $\begin{array}{l}77,67 \pm \\
1,13 *^{2}-4\end{array}$ & $71,09 \pm 1,53^{a}$ & $\begin{array}{l}73,57 \pm \\
185 * 3-4 \\
\end{array}$ & $67,47 \pm 1,61^{n}$ & $65,00 \pm 1,20$ & $70,40 \pm 1,47^{a}$ \\
\hline ЧC $C_{M a k C}$ & $\begin{array}{c}162,17 \pm \\
3,09\end{array}$ & $\begin{array}{r}171,5 \pm \\
4,46 * 1 \cdot 4\end{array}$ & $164,27 \pm 1,43$ & $163,70 \pm 2,76$ & $157,77 \pm 2,10$ & $163,29 \pm 3,03$ & $157,86 \pm 4,30$ & $157,0 \pm 2,92$ \\
\hline САТ макс & $\begin{array}{l}157,21 \pm \\
3,40 * 1-4\end{array}$ & $\begin{array}{l}165,0 \pm \\
4 \quad 44 * 1-4 \\
\end{array}$ & $\begin{array}{l}158,0 \pm \\
2,67 * 2-4\end{array}$ & $\begin{array}{c}147,1 \pm \\
2,71 * 2-4 ;\end{array}$ & 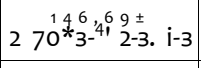 & $138,82 \pm 2,02^{n}$ & $129,86 \pm 3,68$ & $135,6 \pm 3,39$ \\
\hline A A $T_{\text {макс }}$ & $\begin{array}{l}74,77 \pm \\
3,98 * 1 \cdot 4 \\
\end{array}$ & $\begin{array}{c}71,50 \pm \\
8,91 \\
\end{array}$ & $\begin{array}{l}73,13 \pm \\
244 * 2-4 \\
\end{array}$ & $67,60 \pm 4,77$ & $\begin{array}{l}76,000 \pm \\
2,08 * 3-4\end{array}$ & $\begin{array}{c}62,59 \pm \\
3,08 * 3-4 ; 7\end{array}$ & $63,71 \pm 2,74$ & $69,80 \pm 0,80^{a}$ \\
\hline $4 \mathrm{CC}_{5}$ & $105,27 \pm 3,48$ & $111,3 \pm 5,39$ & $106,6 \pm 1,71$ & $111,45 \pm 3,55$ & $\begin{array}{c}92,93 \pm \\
2,14^{* 2111^{3}} \cdot \sim^{3}\end{array}$ & $\begin{array}{cc} & 102,06 \pm \\
2 \quad 02 * 3 \cdot 4,2 \cdot 3: 0\end{array}$ & $100,0 \pm 9,22$ & $112,8 \pm 2,20$ \\
\hline $\mathrm{CAT}_{5}$ & $\begin{array}{l}132,42 \pm \\
1,87 * 1 \cdot 4\end{array}$ & $\begin{array}{l}122,80 \pm \\
3175^{*},-4 ; 7\end{array}$ & $\begin{array}{l}128,27 \pm \\
157 * 2-4\end{array}$ & $\begin{array}{l}115,45 \pm \\
234 * 2-4 ; \bullet\end{array}$ & $\begin{array}{l}123,93 \pm \\
2 \quad 54^{* 13-4_{-} . . i^{-3}} \\
\end{array}$ & $\begin{array}{c}110,94 \pm \\
183 * 3-4 ; 0\end{array}$ & $101,1 \pm 1,76$ & $101,2+3,21$ \\
\hline $\mathrm{AAT}_{5}$ & $\begin{array}{c}79,17 \pm \\
2 \quad 04^{* 1 \cdot 4,1,2,1 \cdot 3} \\
\end{array}$ & $60,83 \pm 3,28^{n}$ & $\begin{array}{l}72,07 \pm \\
2,03 * 2-4 \\
\end{array}$ & $70,27 \pm 1,50 * 2-4$ & $\begin{array}{l}69,29 \pm \\
1 \quad 40 * 3-4 \\
\end{array}$ & $60,88 \pm 2,94^{n}$ & $61,14 \pm 1,35$ & $63,0 \pm 2,0$ \\
\hline $4 \mathrm{CC}_{7}$ & $\begin{array}{c}99,64 \pm \\
2,72 \\
\end{array}$ & $106,67 \pm 5,08$ & $98,67 \pm 1,87$ & $103,45 \pm 2,77$ & $93,31 \pm 1,87$ & $\begin{array}{l}100,50 \pm \\
\wedge \quad 20 * 3-4\end{array}$ & $94,71 \pm 2,62$ & $107,40 \pm 2,16$ \\
\hline $\mathrm{CAT}_{7}$ & $\begin{array}{c}131,42 \pm \\
2,35^{* 1}-4 \cdot \cdot^{\prime}-2 \cdot{ }^{\prime}-3 \\
\end{array}$ & $\begin{array}{l}124,70 \pm \\
4,62 * 1 \cdot 4\end{array}$ & $\begin{array}{l}125,53 \pm \\
1,1 " 7^{*} 2-4\end{array}$ & $116,73 \pm 2,41 * 2-4$ & $\begin{array}{l}121,31 \pm \\
183 * 3-4\end{array}$ & $98,75 \pm 3,71$ & $99,14 \pm 1,50$ & $99,80 \pm 2,77$ \\
\hline ДАТ $_{7}$ & $\begin{array}{l}78,75 \pm \\
1 \quad 38 *,-4\end{array}$ & $\begin{array}{l}78,6,7 \pm \\
3 \quad 34^{*},-4 \\
\end{array}$ & $65,13 \pm 2,63$ & $73,55 \pm 1,85 * 2-4$ & $\begin{array}{l}67,38 \pm \\
1,75 * 34 \\
\end{array}$ & $61,94 \pm 2,87$ & $62,14 \pm 1,63$ & $65,60 \pm 1,25$ \\
\hline $4 C C, 0$ & $97,73 \pm 2,13$ & $103,00 \pm 4,03$ & $\begin{array}{r}98,20 \pm \\
173 * 2-3\end{array}$ & $100,80 \pm 2,20$ & $92,15 \pm 1,60$ & $98,69 \pm 1,39^{a}$ & $94,57 \pm 2,99$ & $95,50 \pm 1,48$ \\
\hline C A T io & 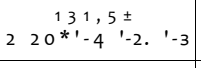 & $\begin{array}{l}114,50 \pm \\
3 \quad 67 * \mid-4 ; 0 \\
\end{array}$ & $\begin{array}{r}125,4 \pm \\
1,51 * 2-4,2-3 \\
\end{array}$ & $\begin{array}{c}116,4 \pm \\
160 * 2-4 ; \pi \\
\end{array}$ & $\begin{array}{l}117,62 \pm \\
203 * 3-4\end{array}$ & $104,25 \pm 1,50^{a}$ & $99,71 \pm 1,72$ & $\begin{array}{c}105,75 \pm \\
0,76^{\circ}\end{array}$ \\
\hline ДАТ, о & $\begin{array}{l}75,17 \pm \\
1,49^{* 1}-4 \\
\end{array}$ & $73,33 \pm 2,89$ & $\begin{array}{l}71,93 \pm \\
1,53 * 2-4 \\
\end{array}$ & $73,01 \pm 1,89$ & $64,0 \pm 2,34$ & $68,38 \pm 1,72$ & $63,00 \pm 1,59$ & $71,25 \pm 1,28^{n}$ \\
\hline
\end{tabular}

Примітки. Тут і в таблиці 2:

1. * - р між групами <0,05.

2. - - р між особами різної статі в групах $<0,05$.

23 Актуальні питання педіатрії, акушерства та гінекології № $\mathbf{1 , 2 0 1 5}$ 


\section{Педіатрія}

Таблиця 2. Показники функціонального резерву серця в дітей з різними формами артеріальної гіпертензії за результатами велоергометричної проби

\begin{tabular}{|c|c|c|c|c|c|c|c|c|}
\hline \multirow[b]{2}{*}{ Показник } & \multicolumn{2}{|c|}{ 1. Стабільна ПАГ ॥ ст. } & \multicolumn{2}{|c|}{ 2. Стабільна ПАГ І ст. } & \multicolumn{2}{|c|}{ 3. Лабільна ПАГ } & \multicolumn{2}{|c|}{ 4. Контрольна група } \\
\hline & $\begin{array}{c}\text { хлопчики, } \\
n=14\end{array}$ & $\begin{array}{c}\text { дівчатка, } \\
n=6\end{array}$ & $\begin{array}{c}\text { хлопчики, } \\
n=15\end{array}$ & $\begin{array}{c}\text { дівчатка, } \\
n=11\end{array}$ & $\begin{array}{c}\text { хлопчики, } \\
n=15\end{array}$ & $\begin{array}{c}\text { дівчатка, } \\
n=17\end{array}$ & $\begin{array}{c}\text { хлопчики, } \\
n=7\end{array}$ & $\begin{array}{c}\text { дівчатка, } \\
n=5\end{array}$ \\
\hline $\mathrm{PWC}_{170}, \mathrm{BT}$ & $\begin{array}{c}226,6+ \\
42,71^{* 1}-4\end{array}$ & $\begin{array}{c}160,0+ \\
8,76^{* 1-4}\end{array}$ & $\begin{array}{l}173,91+ \\
3,46^{* 2}{ }^{2}\end{array}$ & $\begin{array}{c}139,11+ \\
6,65^{* 2} 4 ; n\end{array}$ & $\begin{array}{c}158,8+ \\
5.22^{* 3}{ }^{4}\end{array}$ & $\begin{array}{r}138,87 \pm \\
5 i 53,3-4 ; 0\end{array}$ & $133,75+8,50$ & $106,25+3,14^{\circ}$ \\
\hline $\mathrm{MCK}_{170}$, л/хв & $3.11+0.18^{* 1}{ }^{4}$ & $3,28+0,15^{* 1}-4$ & $\begin{array}{c}3,34 \pm \\
0.07^{* 2}-4\end{array}$ & Q $12,92 \pm$ & $\begin{array}{c}3,12 \pm \\
0,10^{* 3}{ }^{4}\end{array}$ & $\begin{array}{c}2,91+ \\
0,10^{* 3}-4\end{array}$ & $2,65+$ & 2 , \\
\hline BMCK $_{170}$, & $\begin{array}{l}44,99 \pm \\
2.36^{* 1}-4\end{array}$ & 4 & $\begin{array}{l}47,46+ \\
1,3 \Gamma^{2}-4\end{array}$ & 47,4 & $\begin{array}{l}50,56+ \\
124^{\star} 3-4\end{array}$ & $53,81+1,84$ & 5 & $51,77 \pm 1,57^{n}$ \\
\hline XP, пошт/Хв & $72,42 \pm 3,69$ & $\begin{array}{l}79,6 \\
6,59\end{array}$ & $72,6+3,72$ & $70,9+3,18$ & $71,92 \pm 3,69$ & $\begin{array}{l}75,35+ \\
280^{3} 3-4\end{array}$ & $68,57 \pm 2,76$ & $65,0+2,66$ \\
\hline $\mathrm{XP}$, & $0,84 \pm 0,05$ & $0,87 \pm 0,09$ & $0,92 \pm 0,07$ & 05 & 0,89 & $\begin{array}{c}0,90+ \\
0,05^{\star 3 \sim 4}\end{array}$ & 4 &, 03 \\
\hline $\mathrm{IP}, \mathrm{N}$ & 27,08 & $\begin{array}{c}44,17 \pm \\
3 i 05,1-4 ; \Pi\end{array}$ & 31,07 & $\begin{array}{l}30,80+ \\
2,15^{* 1}-2\end{array}$ & $26,69+2,18$ & $32,82 \pm 2,07^{d}$ & $34,0+3,60$ & $33,4 \pm 1,48$ \\
\hline I Pi & $0,21 \pm 0,02$ & $0,37 \pm 0,03 P$ & $0,25+0,02$ & $\begin{array}{c}0,27 \pm \\
0\end{array} 2^{\wedge}$ & $0,23+0,02$ & $0,32 \pm 0,02^{\mathrm{d}}$ & $0,35+0,04$ & $0,32 \pm 0,01$ \\
\hline СНI, ум. од. & $193,85+14,95$ & $171,66+5,59$ & $\begin{array}{c}170,74 \pm \\
4,14\end{array}$ & $\begin{array}{c}201,42 \pm \\
13,30^{\circ}\end{array}$ & $\begin{array}{c}206,67 \pm \\
23,38\end{array}$ & $185,61+7,96$ & $163,32 \pm 7,72$ & $\begin{array}{c}174,46+ \\
10,94\end{array}$ \\
\hline КВРМ, ум. од. & $3.51+0.46^{* 1}{ }^{4}$ & $\begin{array}{c}2,09+ \\
015^{* 1-4, * 1 \sim 3,1 \sim 20}\end{array}$ & $\begin{array}{r}3,23+ \\
020,2-4 \\
\end{array}$ & $4,70+0,76$ & $\begin{array}{c}3,37 \pm \\
0 i 26 * 3-4\end{array}$ & $4,78+0,54^{\circ}$ & $2,44 \pm 0,18$ & $3,28+0,33^{\circ}$ \\
\hline IE РC, ум. од. & $0,469+0,075$ & $0,435+0,044$ & $\begin{array}{c}0,361+ \\
0.0 ю^{* 2}{ }^{2}\end{array}$ & $\begin{array}{c}0,349 \pm \\
0,022^{* 2 \sim 4}\end{array}$ & $\begin{array}{c}0,389+ \\
0.004^{* 3}-4\end{array}$ & $0,396+0,020$ & $0,455+0,031$ & $0,411 \pm 0,015$ \\
\hline
\end{tabular}

дення велоергометричної проби відбувалося відновлення ЧСС до стартових показників. При ПАГ, як стабільній, так і лабільній її формах, на 5-й, 7-й і навіть на 10-й хв фази спокою такого відновлення не відзначали. У дівчаток всіх груп, у тому числі й контрольної, не відбувалось нормалізації ЧСС на 5-й хв фази відновлення. А на 10-й хв відпочинку чСС нормалізувалась тільки у дівчаток контрольної групи.

Як стартові, так і максимальні значення САТ на висоті фізичного навантаження у хлопчиків з ПАГ були вищими порівняно з дівчатками. У фазу відпочинку в хлопчиків усіх груп САТ поступово знижувався, повертаючись до вихідних значень, а у дівчаток зміни САТ різнилися залежно від форми ПАГ. Для дівчаток з лабільною ПАГ було характерним зменшення САТ нижче початкових значень на 7-й хв фази відпочинку, для дівчаток із стабільною ПАГ І ст. - поступове зниження САТ, для дівчаток із стабільною ПАГ II ст. - зростання САТ вище початкових значень на 7-й хв фази відпочинку.

Оцінка реакції ДАТ показала, що в контрольній групі фізичне навантаження призводить до його зниження, що відповідає нормотонічний реакції серцево-судинної системи. В більшості інших груп також було відмічено менші значення ДАТ макс порівняно із стартовими показниками, за винятком хлопчиків 3 лабільною ПАГ, у яких ДАТ макс був вищим, ніж ДАТ 0. На 5-й хв фази відновлення ДАТ знижувався, порівняно з ДАТ макс, у всіх групах, крім дівчаток із стабільною ПАГ І ст., у яких він швидко повернувся до стартових показників, і в хлопчиків із стабільною ПАГ ІІ ст., у яких спостерігалося зростання ДАТ вище стартових показників. На 7-й хв фази відновлення у тих дітей, в яких відзначали зниження ДАТ макс, подальше зменшення ДАТ припинилося, але відбулося збільшення ДАТ вище стартових показників у дівчаток із стабільною ПАГ ІІ ст. На 10-й хв фази відновлення ДАТ стабілізу- вався на рівні початкових значень у всіх дітей, за винятком хлопчиків з лабільною ПАГ, в яких було зафіксовано його нижчі значення порівняно із стартовими показниками. Таким чином, ми виявили, що для дітей з ПАГ характерні коливання ДАТ у фазу відновлення після фізичного навантаження і певні хвилі його підвищення, які, залежно від виду ПАГ, відбуваються в різний час фази відновлення. Найбільш "неспокійним» ДАТ $є$ у хлопчиків із лабільною ПАГ, у яких за 10 хв фази відпочинку спочатку відбулося його підвищення більше стартових показників, потім різке зниження в кінці фази відпочинку.

Показник $\mathrm{PWC}_{170}$, а разом з ним і показник абсолютного МСК були вищими у дітей з ПАГ порівняно 3 контрольною групою, проте показник відносного MCK, що враховує масу дитини, навпаки, в дітей 3 ПАГ (переважно у хлопчиків) був меншим (табл. 2).

У хлопчиків відмічалися тенденції до зниження судинного (інотропний резерв) і підвищення серцевого (хронотропний резерв) компонентів функціонального резерву серця в міру стабілізації гіпертензії, тоді як у дівчаток із стабільною гіпертензією (передусім при стабільній ПАГ ІІ ст.) спостерігалися високі значення як ізотропного, так і хронотропного резервів порівняно 3 контрольною групою.

$\mathrm{CHI}$ був найвищим у хлопчиків з лабільною ПАГ і у дівчаток із стабільною ПАГ । ст., що вказує на найбільше гемодинамічне забезпечення навантаження при цих формах ПАГ.

КВРМ у хлопчиків був вищим, порівняно з контрольною групою, при всіх формах ПАГ. Дівчатка із стабільною ПАГ ІІ ст. мали найменші значення КВРМ порівняно $з$ контрольною групою та іншими формами ПАГ, що вказує на найбільш економне використання резервів міокарда в цій групі.

Як дівчатка, так і хлопчики із стабільною ПАГ ІІ ст. характеризувалися близькими до тих, що були в кон- 


\section{Педіатрія}

трольній групі, значеннями IEPC. Найменш ефективною робота серця виявилася у хлопчиків з лабільною ПАГ і стабільною ПАГІ ст. та в дівчаток із стабільною ПАГ І ст., у яких IЕPC був достовірно меншим порівняно 3 контрольною групою.

Таким чином, велоергометрична проба дозволила більш чітко охарактеризувати адаптаційні процеси в обстежених дітей.

ВИСНОВКИ. 1. Велоергометрична проба дає можливість виявити різну реакцію ЧСС, САТ і ДАТ на фізичне навантаження залежно від статі дитини форми ПАГ, що треба враховувати при розробці лікувально-профілактичних заходів при різних формах ПАГ.

\section{СПИСОК ЛІТЕРАТУРИ}

1. Майданник В. Г. Первинна артеріальна гіпертензія у підлітків: проблемні питання та перспективи / В. Г. Майданник, М. В. Хайтович // Педіатрія, акушерство та гінекологія : наук.-практ. журн. - 2011. T. 73, № 4. - С. 90-91.

2. Коренев Н. М. Артериальная гипертензия подросткового возраста: распространенность, механизмы формирования, подходы к лечению / Н. М. Коренев, Л. Ф. Богмат // Тавр. мед.-биол. вестн. - 2007. T. 10, № 2. - С. 83-87.

3. Недельская Е. В. Циркадные ритмы артериального давления у подростков с гипертензией под
2. Лабільна гіпертензія формується за недостатніх функціональних резервів міокарда та супроводжується підвищеним і неекономним їх витрачанням.

3. Стабілізація гіпертензії супроводжується компенсаторними змінами, що проявляються перерозподілом судинного і серцевого функціональних резервів таким чином, що покращується ефективність роботи серця.

ПЕРСПЕКТИВИ ПОДАЛЬШИХ ДОСЛІДЖЕНЬ. ВИявлені особливості адаптації до фізичного навантаження в дітей з різними формами ПАГ розкривають патогенетичні особливості процесів стабілізації гіпертензії та $€$ перспективними щодо прогнозування стабільного і лабільного перебігу ПАГ та розробки відповідних лікувальних і профілактичних заходів.

влиянием упражнений на велотренажере / Е. В. Недельская // Матеріали науково-практичної конференції. - Харків, 2014. - С. 154-155.

4. Досвід організації фізичної реабілітації підлітків 16-17 років з артеріальною гіпертензією в умовах навчального закладу / О. Г. Іванько, Є. М. Михалюк, В. Я. Підкова [та ін.] // Современная педиатрия. 2014. - № 3 (59). - С. 89-93.

5. Марушко Ю. В. Проблема діагностики і корекції зниженої толерантності до фізичного навантаження у дітей шкільного віку / Ю. В. Марушко, Т. В. Гищак // Современная педиатрия. - 2014. - № 7 (63). - С. 12-16. 